\title{
High-Flow Nasal Oxygenation and Its Applicability in COVID Patients
}

\author{
Raafay Mehmood ${ }^{1}$ (D) Zainab Mansoor $^{1} \cdot$ Gabriel Plamenov Atanasov $^{1} \cdot$ Alexei Cheian $^{1} \cdot$ Alina Davletova $^{1}$. \\ Aman Patel $^{2}$. Danial Ahmed ${ }^{2}$
}

Accepted: 26 January 2022 / Published online: 31 January 2022

(C) The Author(s), under exclusive licence to Springer Nature Switzerland AG 2022

\begin{abstract}
High-flow nasal oxygenation (HFNO) is a type of oxygen therapy that provides humidified and heated oxygen through a nasal cannula at much higher flow rates than standard oxygen therapy, while also allowing control over the fraction of inspired oxygen $\left(\mathrm{FIO}_{2}\right)$. Compared to standard oxygen therapy, it is much more comfortable for the patient and seems to alleviate most of the problems associated with standard oxygen therapy, such as dry nose, dry throat and nasal pain. It also provides a variety of benefits that can reduce the incidence of escalating treatment and initiating mechanical ventilation in COVID patients with acute hypoxemic respiratory failure (AHRF). This article provides an overview of HFNO and its current applications in COVID patients during the pandemic.
\end{abstract}

Keywords High-flow nasal oxygenation · COVID · Anaesthesia $\cdot$ Intensive care · Oxygen therapy $\cdot$ Pre-oxygenation · Respiratory failure

\section{Introduction}

Supplemental oxygen therapy has a vital role in treating critically ill patients, where hospitals have a wide array of modalities to choose from. It is routinely used to maintain adequate oxygen saturation as well as alveolar ventilation. During normal breathing cycles, air is passed through the nose, pharynx, larynx and trachea, where there is significant humidification and heating of the air [1]. In the upper airways, the air is fully saturated with water; however, when given supplemental oxygen, this biological phenomenon ceases, particularly at low flow. This is the primary cause for the symptoms experienced by patients, including dry nose, dry throat and nasal pain, while reducing nasal mucociliary clearance, which results from inhalation of medical gasses that were not humidified and heated [2,3]. Most oxygen supplement devices are limited to no more than $15 \mathrm{~L} / \mathrm{min}$, while the required flow rates for patients with respiratory failure

This article is part of the Topical Collection on Covid-19

Raafay Mehmood

Raafay95@hotmail.com

1 First Faculty of Medicine, Charles University, Prague, Czech Republic

2 King's College London, London, England can be up to 10 times this rate [4]. The large difference between patient inspiratory flow and delivered flow results in an inconsistent inspiratory fraction of oxygen $\left(\mathrm{FIO}_{2}\right)$.

High-flow nasal oxygenation (HFNO) has become increasingly common in many acute care settings, as it minimizes discomfort for the patient associated with low-flow oxygen supplementation, while additionally decreasing the dead space and increasing alveolar ventilation [5]. However, HFNO cannot actively change tidal volume as it is unable to provide an inspiratory push nor an expiratory pull due to its open circuit [6]. HFNO is a supplemental oxygen device that is comprised of an air/oxygen blender, humidifier, nasal cannula and heated tube that can provide a gas flow of up to $70 \mathrm{~L} / \mathrm{min}$ [7]. HFNO is an innovative and more efficient method of delivering supplemental oxygen, which is deemed to be more ideal for patients with respiratory failure as demonstrated by its use during the COVID pandemic [8]. This article will provide an overview of HFNO as well as the role it has played during the COVID pandemic.

\section{High-Flow Nasal Oxygenation}

HFNO is an alternative modality to standard oxygen therapy, which is the result of a multi-decade process to provide a system that could deliver both heated and humidified oxygen 
at high flows. Starting flow rates of $1 \mathrm{~L} / \mathrm{kg} / \mathrm{min}$ with a maximum of $2 \mathrm{~L} / \mathrm{kg} / \mathrm{min}$ are recommended [9]. However, in clinical practice, starting flow rates of 30-40 L/min are routinely used, while up to $70 \mathrm{~L} / \mathrm{min}$ can be delivered. In infants, the flow is typically determined by weight, rarely exceeding 8 $\mathrm{L} / \mathrm{min}$. It is a circuit made up of an air/oxygen blender connected to a nasal cannula via a humidifier and heated tube, which allows for the control of $\mathrm{FIO}_{2}(0.2$ to 1.0$)$ independently of the flow rate [10]. As previously mentioned, due to the humidification and heating of oxygen, patients are relieved of the common symptoms attributed to standard oxygen therapy, such as dry throat and dry mouth.

\section{Mechanisms}

HFNO has a positive role in increasing ventilatory efficiency by a variety of mechanisms. It can constantly flush out carbon dioxide from the nasopharynx, which eliminates the dead space in proportion to the flushed-out volume, increasing $\mathrm{FIO}_{2}[11,12]$. This further allows for a greater proportion of the minute ventilation to participate in gas exchange [13]. Additionally, many studies have shown the effects of HFNO on positive end-expiratory pressure (PEEP) [14-17], which has the potential for application in ICU and perioperative settings as it prevents the cyclical opening and collapsing of alveoli [18]. The airway pressures are dependent on the flow rate, upper airway anatomy, whether breathing through the mouth or nose, and the cannula to nostril size ratio $[16,17,19]$. However, air leakage through the nose and mouth contributes to the variable pressure levels obtained (mean values ranging between 2.7 and $7.4 \mathrm{~cm} \mathrm{H}_{2} \mathrm{O}$ ) [20]. Furthermore, the PEEP effect of HFNO increases tidal volume and end-expiratory lung volume and decreases the respiratory rate and left ventricular afterload, while preserving minute ventilation [21-23]. These alterations in the breathing pattern are a result of recruitment of previously collapsed alveoli or further distention of already ventilated alveoli, similar to the effects achieved with continuous positive airway pressure (CPAP) [24, 25]. This has shown to be beneficial in patients suffering from acute cardiogenic pulmonary oedema and acute heart failure [26, 27].

\section{Indications and Contraindications}

HFNO is indicated in cases of acute hypoxemic respiratory failure (AHRF) of any cause, post-extubation respiratory failure, pulmonary oedema and apnoeic oxygenation and in other respiratory diseases (pneumonia, exacerbation of COPD, bronchitis and bronchiectasis, etc.), where the patients tend to have increased secretions and difficulty expelling them [9]. HFNO is contraindicated in cases of suspected pneumothorax, facial nasal and oropharyngeal and oesophageal trauma. Endotracheal intubation would be preferred in unconscious patients and patients with respiratory failure refractive to HFNO or other non-invasive ventilatory modalities [5].

\section{Effects in Acute Hypoxemic Respiratory Failure}

AHRF can cause respiratory muscle fatigue as well as the loss of airway cells that play a role in the physiological humidification of air, resulting in mucus plugs [28]. HFNO is, therefore, a vital modality to ensure the proper humidification and heating of air to $37^{\circ} \mathrm{C}$, which preserves adequate mucosal function in gas exchange, limiting the metabolic cost of breathing, and preserves the mucosal role in host defences [29]. Additionally, the consistency and volume of respiratory secretions are preserved, as well as the potential to maximize mucociliary clearance. All of these mechanisms contribute to a reduction in the metabolic cost of breathing, which is beneficial especially in patients with AHRF [30, 31]. Furthermore, patients with AHRF typically have larger inspiratory flow rates exceeding those of standard oxygen therapy, which allows entrained room air to dilute the supplemental oxygen, further reducing $\mathrm{FIO}_{2}$ [32]. However, HFNO provides much higher flow rates, which exceeds these patients' inspiratory flow rate, thereby allowing for less dilution of oxygen and delivery of a more desirable $\mathrm{FIO}_{2}$ [33]. HFNO with open mouth breathing tends to dilute the supplemental oxygen reducing the desired $\mathrm{FIO}_{2}$, in contrast to closed mouth nasal breathing with HFNO which raises the $\mathrm{FIO}_{2}$ [34]. Furthermore, studies comparing patients with AHRF oxygenated via a facemask compared to HFNO all demonstrate that HFNO provides better oxygenation, comfort and tolerance; however, oxygenation is only better with HFNO during closed mouth breathing [35-37].

\section{Induction During Anaesthesia}

HFNO also has a variety of roles in the anaesthetic management of patients in the operating theatre during induction and maintenance of anaesthesia. Specifically, patients with anticipated difficult airways, such as morbidly obese patients $\left(\mathrm{BMI}>35 \mathrm{~kg} / \mathrm{m}^{2}\right)$ and patients with underlying airway diseases, are routinely pre-oxygenated using HFNO, as the common technique for intubation in these patients is awake fibre-optic intubation, which exposes them to a higher risk of hypoxemia [38]. Normal facemask ventilation in these patients may only provide a safe apnoea period of 1-3 min following pre-oxygenation compared to $7-10 \mathrm{~min}$ in normal healthy adults since there is a decrease in functional residual capacity and an increased oxygen consumption due to obesity-related physiological changes. HFNO has been shown to improve oxygenation, patient tolerance and safety, as it results in a larger concentration of oxygen available to maintain saturation during apnoeic episodes during long and 
difficult intubations when compared to facemask ventilation in morbidly obese patients [39, 40]. Additionally, in normal cases post-induction, the face mask is removed to attempt tracheal intubation. During this time, there is no oxygen supplied, posing a risk of hypoxemia in case of prolonged intubation [41]. HFNO can prove to be advantageous in these situations, as the nasal cannula does not need to be removed during the insertion of airway devices as well as attempts at laryngoscopy, thus allowing for better oxygenation during these techniques. However, it has been noted that although HFNO provides better oxygenation during the induction process - consistently achieving higher oxygen saturation - this effect ceases after induction, when bag-mask ventilation with a face mask supersedes it in maintaining oxygen saturation post-induction [42], highlighting the superiority of HFNO during the induction phase of anaesthesia.

\section{Application in COVID Patients}

During the COVID pandemic, the SARS-COV-2 virus has spread rapidly throughout the globe, resulting in millions of deaths. The majority of hospitalized COVID patients present with AHRF, with a minority of them requiring treatment in the ICU [43]. COVID patients requiring invasive mechanical ventilation have a mortality rate of about $40 \%$, which added to the limited availability of ICU beds, requires physicians to avoid intubation, when possible. Due to this, the requirements of non-invasive respiratory modalities, such as HFNO, are continuously being adopted to treat patients with AHRF secondary to COVID, where their use has been successful in avoiding escalation of treatment and/or intubation [44-47].

\section{Delayed Tracheal Intubation and Mechanical Ventilation}

HFNO has shown the possibility of reducing the relative risk of requiring invasive ventilation and escalation of oxygen therapy in patients with AHRF [48]. Intubation of patients by anaesthesiologists is a vital component of managing COVID-19 patients, many of whom experience AHRF. Often there is limited time to secure the airways of patients, hence, the use of HFNO may provide a few additional minutes to aid anaesthesiologists in prolonged periods of intubation. A prospective randomized controlled trial was conducted for the use of HFNO-assisted fibre-optic tracheal intubation in critically ill patients which showed a decrease in the time needed to intubate as compared to the standard mask oxygenation group [49]. The HFNO group showed a smaller decrease in $\mathrm{SpO}_{2}$. Furthermore, a meta-analysis that included 31 studies with 5136 participants has concluded that HFNO may reduce the drop in oxygen saturation while treating COVID patients as compared to standard oxygen therapy [50]. Additionally, an observational study in Italy where there is a lack of ICU beds has shown that the use of non-invasive respiratory support such as HFNO is a practical way to decrease unfavourable outcomes outside the ICU setting in patients with COVID [51]. An additional study in Paris, where a total of 138 patients with COVID-related acute respiratory failure were evaluated to compare HFNO to standard oxygen therapy [46], found that only $51 \%$ of those on HFNO required invasive mechanical intubation, compared to $74 \%$ of those on standard oxygen therapy. Furthermore, a South African study included 293 patients with AHRF secondary to COVID [52]. HFNO was delivered at a rate of 50-60 L/min with $\mathrm{FiO}_{2} 0.8-1.0$ aiming to maintain $\mathrm{SpO}_{2} \geq 92 \%$. The rate of successful outcomes was found to be $47 \%$. Higher $\mathrm{SpO}_{2}$, lower heart rate, lower respiratory rate and lower oxygen requirements at the admission predicted a successful outcome. The ratio of $\mathrm{SpO} 2 / \mathrm{FiO} 2$ to respiratory rate measured $6 \mathrm{~h}$ post-HFNO initiation $>3.7$ was found to be $80 \%$ predictive of success. Other studies in non-COVIDrelated AHRF have also concluded that there is reduced requirement for intubation using HFNO [53-55]. These studies show that there is a positive correlation between incorporating HFNO in COVID patients to prevent escalation of disease and further intervention. However, due to the limited data available, the use of HFNO in COVID patients cannot be promoted nor refuted. Its use is limited to guidelines from international and national organizations, expert opinions and institutional culture.

\section{Aerosolization and Spread of Virus Particles}

The aerosolization of infectious particles during the induction of HFNO must be considered for the safety of doctors and nurses [48]. The use of HFNO in COVID patients has been limited due to concerns of increased aerosolization; however, numerous studies suggest it is safe to use, with additional benefit from appropriate personal protective equipment (PPE) worn by the medical workers and face masks worn by the patients. Aerosols are defined as respiratory particles smaller than $5 \mu \mathrm{m}$ [56]. Smoke laser experiments have shown that the use of $60 \mathrm{~L} / \mathrm{min}$ HFNO corresponds to a similar spread of aerosolized infectious particles as compared to standard oxygen therapies [57]. Dispersion of exhaled smoke (aerosol of solid particles $<1$ um) was visualized in a simulation on a manikin model. It revealed that utilizing $\mathrm{HFNO}$ at $60 \mathrm{~L} / \mathrm{min}$ resulted in dispersion comparable to regular oxygen masks at $15 \mathrm{~L} / \mathrm{min}$ and resulted in lower dispersion compared to other methods such as non-rebreathing masks and Venturi masks. Therefore, the airborne transmission of COVID does not appear to be greater in HFNO compared to a regular oxygen mask [57-59]. Surgical masks have also been shown to be 
effective during normal breathing through a computational fluid dynamic simulation study $[60,61]$. In a human patient simulator model, bursts of oxygen flow mimicking coughing bouts suggest that the aerosolization of infectious particles travels a distance on average of no more than $65 \mathrm{~cm}$, which can be further reduced to around $30 \mathrm{~cm}$ with adequate use of a surgical mask on top of the HFNO cannula during coughing [62]. Additionally, the use of surgical masks seems to improve oxygenation when worn on top of HFNO. The use of a surgical mask resulted in an increase in $\mathrm{PaO}_{2}$ and $\mathrm{SaO}_{2}$ [63].

Some theories support HFNO in decreasing aerosolized particles created due to oxygen therapy. One explanation is that aerosol particles are formed via shear stress during turbulent flow and vocal cord vibration $[64,65]$. Coughing produces a flow rate of about $400 \mathrm{~L} / \mathrm{min}$ while HFNO uses $60 \mathrm{~L} / \mathrm{min}$ which might not be sufficient to create aerosols [66, 67]. Another theory involves the opening of closed bronchioles which in turn releases particles from the walls of the bronchioles. In case the latter theory is correct, the use of HFNO therapy can be beneficial as it creates a PEEP, which hinders the closure of smaller bronchioles [68]. In conclusion, even though the aerosolization of infectious particles is possible, it appears to be not as severe as previously thought. The use of a surgical mask on top of the HFNO cannula in addition to the use of PPE by hospital staff should minimize the spread of COVID aerosols.

\section{Conclusion}

In summary, HFNO is a type of oxygen supplemental therapy that can deliver oxygen at high flow rates up to $70 \mathrm{~L} /$ min, while simultaneously being able to provide a $\mathrm{FIO}_{2}$ between 0.21 and 1.0. It has numerous physiological effects such as pharyngeal dead space washout, a reduction in the work of breathing, a PEEP effect, constant $\mathrm{FIO}_{2}$ release and increased mucociliary clearance, all of which are useful in treating patients presenting with AHRF secondary to COVID. The use of HFNO in COVID patients has reduced the need to intubate or escalate treatment in approximately $50 \%$ of cases and with no increased risk of aerosol transmission compared to standard facemasks, HFNO is a viable candidate to manage COVID patients and help aid the ICU bed shortage in the pandemic.

Author Contribution All authors contributed to the manuscript idea and design. Material preparation, data collection and analysis were performed by all authors. The first draft of the manuscript was written by Raafay Mehmood and Zainab Mansoor, while all authors commented on previous versions of the manuscript. All authors read and approved the final manuscript.
Availability of Data and Material (Data Transparency) Not applicable.

Code Availability Not applicable.

\section{Declarations}

Ethics Approval Not applicable.

Consent to Participate Not applicable.

Consent for Publication Not applicable.

Conflict of Interest The authors declare no competing interests.

\section{References}

1. Rouadi P, Baroody FM, Abbott D, et al (1999) A technique to measure the ability of the human nose to warm and humidify air. J Appl Physiol. https://doi.org/10.1152/jappl.1999.87.1.400

2. Chanques G, Constantin JM, Sauter M, et al (2009) Discomfort associated with underhumidified high-flow oxygen therapy in critically ill patients. Intensive Care Med. https://doi.org/10.1007/ s00134-009-1456-x

3. Salah B, Dinh Xuan AT, Fouilladieu JL, et al (1988) Nasal mucociliary transport in healthy subjects is slower when breathing dry air. Eur Respir J

4. L'Her E, Deye N, Lellouche F, et al (2005) Physiologic effects of noninvasive ventilation during acute lung injury. Am J Respir Crit Care Med. https://doi.org/10.1164/rccm.200402-226OC

5. Girou E, Brun-Buisson C, Taillé S, et al (2003) Secular Trends in Nosocomial Infections and Mortality Associated with Noninvasive Ventilation in Patients with Exacerbation of COPD and Pulmonary Edema. J Am Med Assoc. https://doi.org/10.1001/ jama.290.22.2985

6. Nishimura M (2015) High-flow nasal cannula oxygen therapy in adults. J. Intensive Care

7. Nishimura M. High-Flow Nasal Cannula Oxygen Therapy in Adults: Physiological Benefits, Indication, Clinical Benefits, and Adverse Effects. Respir Care. 2016;61:529-41. https://doi.org/10. 4187/respcare.04577.

8. Alhazzani W, Møller MH, Arabi YM, et al. Surviving Sepsis Campaign: guidelines on the management of critically ill adults with Coronavirus Disease 2019 (COVID-19). Intensive Care Med. 2020;46:854-87. https://doi.org/10.1007/s00134-020-06022-5.

9. Spoletini G, Alotaibi M, Blasi F, Hill NS. Heated Humidified High-Flow Nasal Oxygen in Adults. Chest. 2015;148:253-61. https://doi.org/10.1378/chest.14-2871.

10. Roca O, Riera J, Torres F, Masclans JR (2010) High-flow oxygen therapy in acute respiratory failure. Respir Care

11. Bräunlich J, Beyer D, Mai D, et al (2013) Effects of nasal high flow on ventilation in volunteers, COPD and idiopathic pulmonary fibrosis patients. Respiration. https://doi.org/10.1159/000342027

12. Wood KE, Flaten AL, Backes WJ (2000) Inspissated secretions: A life-threatening complication of prolonged noninvasive ventilation. Respir Care

13. Parke R, McGuinness S, Dixon R, Jull A. Open-label, phase II study of routine high-flow nasal oxygen therapy in cardiac surgical patients. Br J Anaesth. 2013. https://doi.org/10.1093/bja/aet262.

14. Kilgour E, Rankin N, Ryan S, Pack R (2004) Mucociliary function deteriorates in the clinical range of inspired air temperature and humidity. Intensive Care Med. https://doi.org/10.1007/ s00134-004-2235-3 
15. Chidekel A, Zhu Y, Wang J, et al (2012) The effects of gas humidification with High-flow nasal cannula on cultured human airway epithelial cells. Pulm Med. https://doi.org/10.1155/2012/ 380686

16. Groves N, Tobin A (2007) High flow nasal oxygen generates positive airway pressure in adult volunteers. Aust Crit Care. https://doi.org/10.1016/j.aucc.2007.08.001

17. Ritchie JE, Williams AB, Gerard C, Hockey H (2011) Evaluation of a humidified nasal high-flow oxygen system, using oxygraphy, capnography and measurement of upper airway pressures. Anaesth Intensive Care. https://doi.org/10.1177/03100 $57 \times 1103900620$

18. Vargas M, Sutherasan Y, Gregoretti C, Pelosi P (2014) PEEP role in ICU and operating room: From pathophysiology to clinical practice. Sci. World J.

19. Parke R, McGuinness S, Eccleston M (2009) Nasal highflow therapy delivers low level positive airway pressure. Br J Anaesth. https://doi.org/10.1093/bja/aep280

20. Chanques G, Riboulet F, Molinari N, et al (2013) Comparison of three high flow oxygen therapy delivery devices: A clinical physiological cross-over study. Minerva Anestesiol

21. Corley A, Caruana LR, Barnett AG, et al (2011) Oxygen delivery through high-flow nasal cannulae increase end-expiratory lung volume and reduce respiratory rate in post-cardiac surgical patients. Br J Anaesth. https://doi.org/10.1093/bja/aer265

22. Mündel T, Feng S, Tatkov S, Schneider H (2013) Mechanisms of nasal high flow on ventilation during wakefulness and sleep. J Appl Physiol. https://doi.org/10.1152/japplphysiol.01308.2012

23. Riera J, Pérez P, Cortés J, et al (2013) Effect of high-flow nasal cannula and body position on end-expiratory lung volume: A cohort study using electrical impedance tomography. Respir Care. https://doi.org/10.4187/respcare.02086

24. Katz JA, Marks JD (1985) Inspiratory work with and without continuous positive airway pressure in patients with acute respiratory failure. Anesthesiology. https://doi.org/10.1097/00000 542-198512000-00008

25. Bikker IG, van Bommel J, Miranda DR, et al (2008) End-expiratory lung volume during mechanical ventilation: A comparison with reference values and the effect of positive end-expiratory pressure in intensive care unit patients with different lung conditions. Crit Care. https://doi.org/10.1186/cc7125

26. Lacroix G, Pons F, D'Aranda E, et al (2013) High-flow oxygen, a therapeutic bridge while awaiting thrombolysis in pulmonary embolism? Am J Emerg Med. https://doi.org/10.1016/j.ajem. 2012.08.030

27. Carratalá Perales JM, Llorens P, Brouzet B, et al (2011) HighFlow Therapy via Nasal Cannula in Acute Heart Failure. Rev Española Cardiol (English Ed. https://doi.org/10.1016/j.rec. 2010.10.035

28. Dysart K, Miller TL, Wolfson MR, Shaffer TH (2009) Research in high flow therapy: Mechanisms of action. Respir Med

29. Sim MAB, Dean P, Kinsella J, et al (2008) Performance of oxygen delivery devices when the breathing pattern of respiratory failure is simulated. In: Anaesthesia

30. Sztrymf B, Messika J, Mayot T, et al (2012) Impact of high-flow nasal cannula oxygen therapy on intensive care unit patients with acute respiratory failure: A prospective observational study. J Crit Care. https://doi.org/10.1016/j.jcrc.2011.07.075

31. Lenglet H, Sztrymf B, Leroy C, et al (2012) Humidified high flow nasal oxygen during respiratory failure in the emergency department: Feasibility and efficacy. Respir Care https://doi.org/ 10.4187/respcare. 01575

32. Kallstrom TJ (2002) AARC Clinical Practice Guideline: oxygen therapy for adults in the acute care facility--2002 revision \& update. Respir Care
33. Spence CJT, Buchmann NA, Jermy MC (2012) Unsteady flow in the nasal cavity with high flow therapy measured by stereoscopic PIV. Exp Fluids. https://doi.org/10.1007/s00348-011-1044-Z

34. Saslow JG, Aghai ZH, Nakhla TA, et al (2006) Work of breathing using high-flow nasal cannula in preterm infants. J Perinatol https://doi.org/10.1038/sj.jp.7211530

35. Tiruvoipati R, Lewis D, Haji K, Botha J (2010) High-flow nasal oxygen vs high-flow face mask: A randomized crossover trial in extubated patients. J Crit Care. https://doi.org/10.1016/j.jcrc.2009. 06.050

36. Calvano TP, Sill JM, Kemp KR, Chung KK (2008) Use of a highflow oxygen delivery system in a critically ill patient with dementia. Respir Care

37. Pillai A, Daga V, Lewis J, et al (2016) High-flow humidified nasal oxygenation vs. standard face mask oxygenation. Anaesthesia. https://doi.org/10.1111/anae.13607

38. Badiger S, John M, Fearnley RA, et al (2015) Optimizing oxygenation and intubation conditions during awake fibre-optic intubation using a high-flow nasal oxygen-delivery system. $\mathrm{Br} \mathbf{J}$ Anaesth. https://doi.org/10.1093/bja/aev262

39. Patel A, Nouraei SAR (2015) Transnasal Humidified RapidInsufflation Ventilatory Exchange (THRIVE): A physiological method of increasing apnoea time in patients with difficult airways. Anaesthesia. https://doi.org/10.1111/anae.12923

40. (2014) Benefits of Heated and Humidified High Flow Nasal Oxygen for Preoxygenation in Morbidly Obese Patients Undergoing Bariatric Surgery: A Randomized Controlled Study. J Obes Bariatrics. https://doi.org/10.13188/2377-9284.1000003

41. Kim HJ, Asai T (2019) High-flow nasal oxygenation for anesthetic management. Korean J. Anesthesiol.

42. Ng I, Krieser R, Mezzavia P, et al (2018) The Use of Transnasal Humidified Rapid-Insufflation Ventilatory Exchange (THRIVE) for Pre-Oxygenation in Neurosurgical Patients: A Randomised Controlled Trial. Anaesth Intensive Care. https://doi.org/10.1177/ $0310057 X 1804600403$

43. Gorman E, Connolly B, Couper K, et al (2021) Non-invasive respiratory support strategies in COVID-19. Lancet Respir. Med.

44. Wang K, Zhao W, Li J, et al (2020) The experience of high-flow nasal cannula in hospitalized patients with 2019 novel coronavirus-infected pneumonia in two hospitals of Chongqing, China. Ann Intensive Care. https://doi.org/10.1186/s13613-020-00653-Z

45. Patel M, Gangemi A, Marron R, et al (2020) Retrospective analysis of high flow nasal therapy in COVID-19-related moderate-tosevere hypoxaemic respiratory failure. BMJ Open Respir Res.

46. Bonnet N, Martin O, Boubaya M, et al (2021) High flow nasal oxygen therapy to avoid invasive mechanical ventilation in SARSCoV-2 pneumonia: a retrospective study. Ann Intensive Care. https://doi.org/10.1186/s13613-021-00825-5

47. Demoule A, Baron AV, Darmon M, et al (2020) High-flow nasal cannula in critically Ill patients with severe COVID-19. Am J Respir Crit Care Med

48. Agarwal A, Basmaji J, Muttalib F, et al (2020) High-flow nasal cannula for acute hypoxemic respiratory failure in patients with COVID-19: systematic reviews of effectiveness and its risks of aerosolization, dispersion, and infection transmission. Can J Anesth

49. Wu CN, Xia LZ, Li KH, et al (2020) High-flow nasal-oxygenation-assisted fibreoptic tracheal intubation in critically ill patients with COVID-19 pneumonia: a prospective randomised controlled trial. Br J Anaesth

50. Lewis SR, Baker PE, Parker R, Smith AF (2021) High-flow nasal cannulae for respiratory support in adult intensive care patients. Cochrane Database Syst Rev 2021: https://doi.org/10.1002/14651 858.CD010172.pub3

51. Franco C, Facciolongo N, Tonelli R, et al (2020) Feasibility and clinical impact of out-of-ICU noninvasive respiratory support in 
patients with COVID-19-related pneumonia. Eur Respir J. https:// doi.org/10.1183/13993003.02130-2020

52. Calligaro GL, Lalla U, Audley G, et al (2020) The utility of highflow nasal oxygen for severe COVID-19 pneumonia in a resourceconstrained setting: A multi-centre prospective observational study. EClinicalMedicine. https://doi.org/10.1016/j.eclinm.2020. 100570

53. Li J, Jing G, Scott JB (2020) Year in review 2019: High-flow nasal cannula oxygen therapy for adult subjects. Respir Care

54. Lyons C, Callaghan M (2020) The use of high-flow nasal oxygen in COVID-19. Anaesthesia

55. Rochwerg B, Granton D, Wang DX, et al (2019) High-flow nasal cannula compared with conventional oxygen therapy for acute hypoxemic respiratory failure: author's reply. Intensive Care Med.

56. Wilson NM, Norton A, Young FP, Collins DW (2020) Airborne transmission of severe acute respiratory syndrome coronavirus-2 to healthcare workers: a narrative review. Anaesthesia

57. Hui DS, Chow BK, Lo T, et al (2019) Exhaled air dispersion during high-flow nasal cannula therapy versus CPAP via different masks. Eur Respir J. https://doi.org/10.1183/13993003. 02339-2018

58. Ip M, Tang JW, Hui DSC, et al (2007) Airflow and droplet spreading around oxygen masks: A simulation model for infection control research. Am J Infect Control. https://doi.org/10.1016/j.ajic. 2007.05.007

59. Li J, Fink JB, Ehrmann S (2020) High-flow nasal cannula for COVID-19 patients: Low risk of bio-aerosol dispersion. Eur Respir J

60. Leonard S, Atwood CW, Walsh BK, et al (2020) Preliminary Findings on Control of Dispersion of Aerosols and Droplets During High-Velocity Nasal Insufflation Therapy Using a Simple Surgical Mask: Implications for the High-Flow Nasal Cannula Chest https://doi.org/10.1016/j.chest.2020.03.043
61. Wei H, Jiang B, Behringer EC, et al (2021) Controversies in airway management of COVID-19 patients: updated information and international expert consensus recommendations. Br J Anaesth. https://doi.org/10.1016/j.bja.2020.10.029

62. Hui DS, Chow BK, Chu L, et al (2012) Exhaled Air Dispersion during Coughing with and without Wearing a Surgical or N95 Mask. PLoS One. https://doi.org/10.1371/journal.pone.0050845

63. Montiel V, Robert A, Robert A, et al (2020) Surgical mask on top of high-flow nasal cannula improves oxygenation in critically ill COVID-19 patients with hypoxemic respiratory failure. Ann Intensive Care. https://doi.org/10.1186/s13613-020-00744-x

64. Bourouiba L, Dehandschoewercker E, Bush JWM (2014) Violent expiratory events: On coughing and sneezing. J Fluid Mech. https://doi.org/10.1017/jfm.2014.88

65. Gregg I, Nunn AJ (1973) Peak Expiratory Flow in Normal Subjects. Br Med J. https://doi.org/10.1136/bmj.3.5874.282

66. Asadi S, Wexler AS, Cappa CD, et al (2019) Aerosol emission and superemission during human speech increase with voice loudness. Sci Rep. https://doi.org/10.1038/s41598-019-38808-z

67. Leiner GC, Abramowitz S, Small MJ, et al (1963) Expiratory peak flow rate. standard values for normal subjects. Use as a clinical test of ventilatory function. Am Rev Respir Dis. https://doi.org/ 10.1164/arrd.1963.88.5.644

68. Gaeckle NT, Lee J, Park Y, et al (2020) Aerosol generation from the respiratory tract with various modes of oxygen delivery. Am J Respir Crit Care Med. https://doi.org/10.1164/rccm. 202006-2309OC

Publisher's Note Springer Nature remains neutral with regard to jurisdictional claims in published maps and institutional affiliations. 